\title{
Evaluasi Kondisi Jalan Lingkungan Rumah Sakit Umum Dr. Kanujoso Djatiwibowo Balikpapan Rahmat $^{1^{*}}$; Martheana Kencanawati ${ }^{2}$; Suheria Muliadevi ${ }^{3}$ \\ ${ }^{1}$ Univerrsitas Balikpapan \\ ${ }^{1}$ rahmat.uniba@uniba-bpn.ac.id
}

\begin{abstract}
Abstrak
Pemeliharaan jalan adalah untuk mempertahankan kondisi jalan yang sesuai dengan tingkat pelayanan dan kemampuannya pada saat jalan tersebut selesai dibangun dan dioperasikan sampai dengan tercapainya umur rencana yang telah ditentukan. Bertitik tolak dari kondisi tersebut, pemeliharaan jalan perlu dilakukan secara terus-menerus/rutin dan berkesinambungan. Penanganan pemeliharaan jalan dapat dilakukan secara rutin maupun berkala. Pemeliharaan jalan secara rutin dilakukan secara terus-menerus sepanjang tahun dan dilakukan sesegera mungkin ketika kerusakan yang terjadi belum meluas. Perawatan dan perbaikan dilakukan pada tahap kerusakan masih ringan dan setempat. Hal ini dilakukan sehubungan dengan biaya perbaikannya yang relatif rendah dan cara memperbaikinyapun relatif mudah/ringan. Kondisi jalan lingkungan Rumah Sakit Umum Daerah Dr. Kanujoso Djatiwibowo saat ini (existing) dengan menggunakan perkerasan beton (rigid pavement) dimana Jalan lingkungan Rumah Sakit Umum Daerah Dr. Kanujoso Djatiwibowo ditumbuhi banyak vegetasi/tanaman air terapung yang ditemukan pada saat dilakukan pemantauan lapangan. Dari hasil pengamatan Jalan Lingkungan juga dikelilingi oleh tanaman alang-alang dan tanaman merambat sehingga kesan kumuh dan tidak terawat.
\end{abstract}

Kata Kunci: Pemeliharaan jalan, perkerasan beton

\section{Abstract}

Road maintenance is to maintain road conditions that are in accordance with the level of service and capabilities when the road is completed and operated until the specified age of the plan is reached. Starting from these conditions, road maintenance needs to be carried out continuously / routinely and continuously. Handling road maintenance can be done regularly or periodically. Road maintenance is routinely carried out continuously throughout the year and is carried out as soon as possible when the damage has not been widespread. Care and repairs carried out at the stage of damage are still mild and local. This is done in connection with the relatively low repair costs and how to fix it is relatively easy / light. Environmental conditions of the Regional General Hospital Dr. Kanujoso Djatiwibowo currently (existing) using concrete pavement (rigid pavement) where the neighborhood Road General Hospital Dr. Kanujoso Djatiwibowo is overgrown with a lot of floating vegetation / water plants found during field monitoring. From the results of observations on Jalan Lingkungan, it is also surrounded by reeds and vines so that the impression is slum and not maintained.

Keywords: Road maintenance, concrete pavement

\section{Pendahuluan}

Pemeliharaan jalan adalah untuk mempertahankan kondisi jalan mantap sesuai dengan tingkat pelayanan dan kemampuannya pada saat jalan tersebut selesai dibangun dan dioperasikan sampai dengan tercapainya umur rencana yang telah ditentukan.Bertitik tolak dari kondisi mantap tersebut, pemeliharaan jalan perlu dilakukan secara terus-menerus/rutin dan berkesinambungan. Tanpa pemeliharaan dan perbaikan jalan secara memadai, baik rutin maupun berkala, akan dapat mengakibatkan kerusakan yang besar pada jalan, sehingga jalan akan lebih cepat kehilangan fungsinya.

Jalan beton semen atau perkerasan kaku terdiri dari slab dan lapis pondasi beton. Apabila perkerasan kaku dipelihara dengan baik dan tetap dalam kondisi yang baik, maka jalan beton semen tersebut akan

Volume 1, Nomor 1, 2019

ISSN 2657-1439 mempunyai umur lebih lama dari pada jalan aspal. Tetapi sekali jalan beton ini mulai rusak, maka kerusakan itu berlangsung sangat cepat. Oleh karena itu sangat penting untuk melakukan pemeliharaan yang bersifat pencegahan seperti menutup sambungan atau retakretak dan memperbaiki kerusakan-kerusakan, yang timbul, dan menemukan penyebab-penyebabnya dengan melakukan pemeriksaan (inspeksi) secara rutin.

Terdapat tiga hal yang menjadi tujuan pemeriksaan rutin dalam pemeliharaan jalan, adalah menghilangkan penyebab kerusakan perkerasan jalan dan membuat langkah-langkah pencegahan, menemukan lokasi kerusakan jalan pada tahap sedini mungkin, untuk dilakukan penanganan sementara dan merencanakan perbaikan secepat mungkin, dan mempertimbangkan 
pengaruh pelaksanaan perbaikan terhadap lalu-lintas dan lingkungan di sepanjang jalan.

Penanganan pemeliharaan jalan dapat dilakukan secara rutin maupun berkala. Pemeliharaan jalan secara rutin dilakukan secara terus-menerus sepanjang tahun dan dilakukan sesegera mungkin ketika kerusakan yang terjadi belum meluas. Perawatan dan perbaikan dilakukan pada tahap kerusakan masih ringan dan setempat. Hal ini dilakukan sehubungan dengan biaya perbaikannya yang relatif rendah dan cara memperbaikinyapun relatif mudah/ringan.

\section{Data Jalan Lingkungan}

Berikut data terkait Perkerasan Jalan Lingkungan Rumah Sakit Umum Daerah Dr. Kanujoso Djatiwibowo:

a. Panjang Jalan Lingkungan : 1.950 meter

b. Jenis Perkerasan : Beton K-225

c. Lebar Jalan Lingkungan Perkerasan Beton : 1,5 meter dengan Tebal Jalan Lingkungan Perkerasan Beton : 10 centimeter

d. Tulangan Beton menggunakan Wire Mess M6

Jalan lingkungan Rumah Sakit Umum Daerah Dr. Kanujoso Djatiwibowo di fungsikan sebagai jalan inspeksi terhadap keamanan batasan wilayah dari rumah sakit.
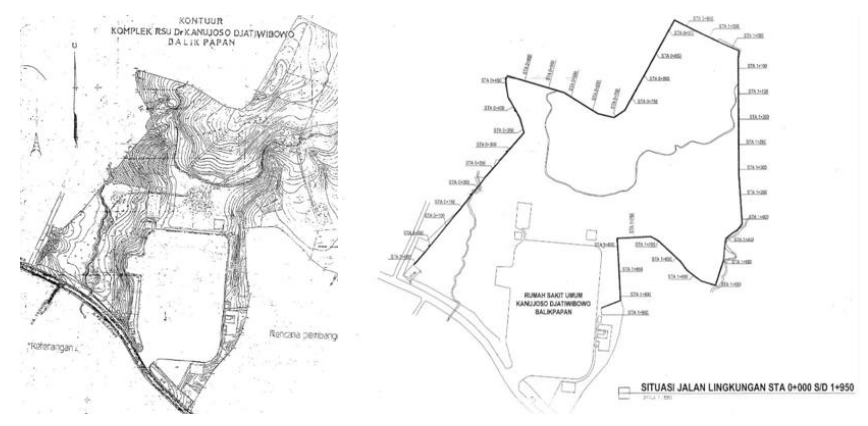

Gambar 1. Kontur dan situasi tanah Rumah Sakit Umum r.... n.......... n:_.........

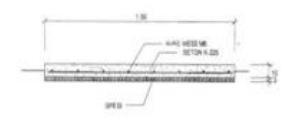

DETAIL POTONGAN STA $0+000$ SID STA $1+400$ STA $1+800$ S/D STA $1+950$

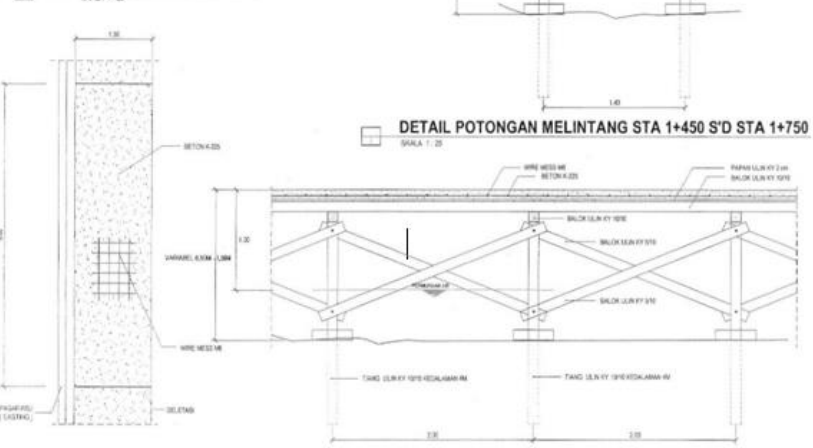

DETAIL DENAH JALAN LINGKUNGAN

DETALL POTONGAN MEMANJANG STA 1+450 S'D STA $1+750$

Gambar 2. Detail Jalan Lingkungan STA 0+000 s/d 1+950

Volume 1, Nomor 1, 2019

ISSN 2657-1439
Berdasarkan pada gambar 1 dan gambar 2, kondisi sesungguhnya jalan lingkungan Rumah Sakit Umum Daerah Dr. Kanujoso Djatiwibowo, kondisi sesunggunya dilapangan adalah:

a) Kondisi jalan lingkungan Rumah Sakit Umum Daerah Dr. Kanujoso Djatiwibowo saat ini (existing) dengan menggunakan perkerasan beton (rigid pavement)

b) Jalan lingkungan Rumah Sakit Umum Daerah Dr. Kanujoso Djatiwibowo ditumbuhi banyak vegetasi/tanaman air terapung yang ditemukan pada saat dilakukan pemantauan lapangan. Dari hasil pengamatan Jalan Lingkungan juga dikelilingi oleh tanaman alang-alang dan tanaman merambat sehingga kesan kumuh dan tidak terawat (gambar 3).

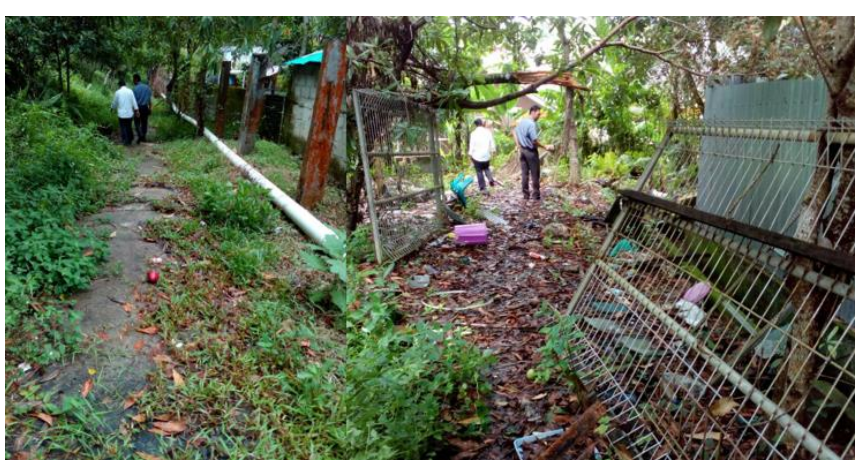

Gambar 3. Kondisi Existing kesan kumuh dan tidak terawat

\section{Hasil dan Pembahasan}

Mutu pelaksanaan dari kegiatan pemeliharan rutin dimonitor dan dipantau sesuai dengan tingkat kerusakan yang perlu segera diperbaiki dan ditindak lanjuti. Tanggungjawab seorang petugas pada suatu kegiatan pemeliharaan jalan adalah bagaimana yang bersangkutan dapat menjamin dipenuhinya tata cara penanganan jenisjenis kerusakan yang telah disyaratkan dalam pemeliharaan rutin tersebut. Sehubungan dengan itu, ada beberapa hal yang perlu mendapatkan perhatian, antara lain sebagai berikut:

a. Melakukan monitoring dan pantauan secara terusmenerus terhadap kondisi jalan sesuai dengan kewenangan dan tanggungjawab masing-masing.

b. Melakukan pencatatan yang dituangkan dalam bentuk laporan harian, tingkat dan jenis kerusakan yang ada.

c. Melakukan usaha perbaikan sesuai tata cara yang dipersyaratkan dalam kegiatan pemeliharaan jalan.

d. Melaporkan segera kepada atasan masing-masing bila terjadi hal-hal diluar kemampuannya yang tidak dapat diatasi sesuai dengan prosedur yang telah ditentukan.

Hasil akhir dari suatu pekerjaan pemeliharaan rutin jalan perlu dicatat dan dievaluasi serta dilaporkan secara 
periodik; harian, mingguan, bulanan, triwulanan, dan final/akhir.

Kuantitas hasil akhir yang perlu diperhatikan adalah sebagai berikut:

1. Kerataan permukaan dari struktur; menampilkan hasil akhir pekerjaan yang berkualitas, sama seperti keadaan baru atau kembali seperti semula.

2. Kepadatan; pada lapisan perkerasan telah dicapai tingkat kepadatan yang sesuai dengan peran dan fungsinya dalam struktur.

3. Bentuk; hasil akhir sesuai dengan bentuk yang telah direncanakan (gambar rencana/kerja).

4. Fungsi; setelah dilakukan pemeliharaan/perbaikan, dapat berfungsi secara baik dan benar, misal kelancaran air pada saluran tepi / tidak tersumbat.

5. Toleransi; perbedaan/selisih dari hasil akhir pekerjaan masih dalam batas-batas atau koridor yang disyaratkan (tidak berpotensi menimbulkan kerusakan).

6. Jumlah; kuantitas hasil akhir pekerjaan sesuai dengan kuantitas yang telah direncanakan dalam pemeliharaan/perbaikan.

Terjadinya kerusakan pada suatu struktur perlu diketahui dimana lokasi kerusakannya, jenis kerusakannya, dan dimensi kerusakannya. Hal ini perlu segera diketahui agar penanganannya dapat sesuai dengan jenis sumber daya yang perlu disiapkan/disediakan.

1. Lokasi kerusakan;

a. harus diketahui dengan jelas agar dapat segera dilakukan pengiriman petugas pemeliharaan dan kelengkapannya untuk melakukan perbaikan.

b. Setiap lokasi kerusakan sudah diberi tanda (misal; cat semprot), dan dicatat untuk bahan laporan/inventarisasi.

2. Jenis kerusakan;

a. Jenis kerusakan yang terjadi perlu diketahui untuk memastikan upaya perbaikannya yang menyangkut masalah teknologi konstruksi.

b. Setiap jenis kerusakan perlu diinventarisasi untuk keperluan laporan evaluasi selanjutnya.

3. Dimensi kerusakan;

a. Dimensi kerusakan yang terjadi perlu diketahui guna memastikan tingkat kerusakan dan volume kerusakan yang terjadi sehingga dapat dipersiapkan tenaga pekerja, bahan, alat, metode/cara, dan biaya yang sesuai.

b. Setiap dimensi kerusakan diinventarisasi untuk keperluan laporan dan analisa perhitungan selanjutnya, khususnya dalam mempersiapkan rencana anggaran biaya yang diperlukan.
Untuk mendukung sistem pelaporan sesuai dengan kondisi di lapangan, laporan dilakukan dalam tahapan dan jenis keperluannya. Jenis laporan yang lazim dilakukan adalah;

1. Laporan Harian;

Semua kegiatan pekerjaan di lapangan dan hal-hal yang terkait dengan pekerjaan, dicatat/direkam setiap hari, dan dituangkan dalam bentuk laporan harian. Dalam laporan harian tersebut antara lain dicatat semua kejadian yang ada di lapangan seperti;

a. Jenis kegiatan/pekerjaan yang dilakukan pada hari itu.

b. Kondisi pekerjaan saat itu.

c. Cuaca yang terjadi sepanjang hari.

d. Hal-hal terkait/mendukung terselenggaranya pekerjaan pada hari yang bersangkutan.

e. engunjung/tamu proyek, saran, dan pendapat secara umum.

f. Hal penting lainnya yang mungkin berdampak negatif terhadap penyelenggaraan kegiatan di lapangan.

\section{Laporan Mingguan;}

Laporan mingguan merupakan rangkuman laporan harian selama periode waktu dalam satu minggu, disertai prestasi kerja selama satu minggu. Dalam hubungan ini, prestasi kerja selama satu minggu tersebut dapat dilihat kecenderungannya; positif ataukah negatif. Apakah kegiatan pekerjaan berjalan lancar sesuai jadual ataukah mengalami hambatan sehingga terlambat/tertunda; belum sesuai yang telah direncanakan.

3. Laporan Bulanan;

Laporan bulanan merupakan rangkuman laporan mingguan selama periode waktu dalam satu bulan. Dalam hubungan ini, prestasi kerja dalam satu bulan akan menunjukkan jenis kegiatan yang berlangsung sesuai jadual maupun yang terlambat/tidak-belum sesuai jadual. Prestasi kerja yang telah dilakukan selama periode satu bulan tersebut dapat segera ditentukan apakah positif ataukah negatif.

Hasil/prestasi kerja dapat digunakan sebagai bahan untuk mengevaluasi suatu penyelenggaraan proyek, agar dapat segera diketahui kendala-kendala yang timbul selama proses kegiatan dalam satu bulan, untuk mengambil keputusan mengenai langkah-langkah dan tindak lanjut yang perlu dilakukan oleh Pemimpin Proyek/Pemimpin Bagian Proyek.

4. Laporan Triwulanan;

Dalam laporan triwulanan dapat dilihat aktivitas setiap bulan yang dirangkum dalam tiga bulan berturutturut. Pada laporan tersebut sudah dapat dilihat kemungkinan-kemungkinan yang akan terjadi untuk periode berikutnya. 
Oleh karena itu, langkah-langkah yang telah diputuskan dapat dievaluasi dan direvisi kembali bila masih belum dapat mengatasi keterlambatan maupun penyimpangan yang telah terjadi sebelumnya.

5. Laporan Akhir / Final Report;

Laporan akhir merupakan rangkuman dari seluruh kegiatan selama pelaksanaan pekerjaan dari awal sampai akhir pelaksanaan. Dalam laporan akhir tersebut, dapat dilihat perkembangan prestasi pekerjaan maupun biaya yang telah dikeluarkan untuk melaksanakan pekerjaan sesuai jadual yang telah ditentukan. Selain itu, dapat dilihat pula revisi maupun perubahan-perubahan yang dilakukan guna mencapai target yang dimaksud sebelumnya.

\section{Kesimpulan dan Saran}

Pemeliharaan jalan secara berkala dilakukan secara berkala dengan melakukan pula peremajaan terhadap bahan perkerasan maupun bahan lainnya. Selain itupun, dilakukan perataan kembali terhadap permukaan jalan. Baik pemeliharaan rutin maupun pemeliharaan berkala, tidak dimaksudkan untuk meningkatkan kemampuan struktur.

Sehubungan dengan hal tersebut, pengendalian dan pengawasan pemeliharaan jalan perlu dilakukan secara rutin maupun berkala agar kerusakan jalan beserta bangunan. pelengkap dan fasilitas pendukungnya sejak dini dapat diditeksi jenis dan volume serta cara penanganan yang harus dilakukan segera. Selain itupun perlu diketahui lokasi kerusakannya, khususnya pada lokasi tertentu yang selalu terjadi kerusakan berulang.

\section{Ucapan Terima Kasih}

Bagian ini berisi ucapan terima kasih terutama ditujukan kepada Rumah Sakit Umum Daerah Dr. Kanujoso Djatiwibowo dan pihak lain yang ikut membantu kegiatan evaluasi kondisi jalan lingkungan di Rumah Sakit Umum Daerah Dr. Kanujoso Djatiwibowo.

\section{Daftar Rujukan}

Peraturan Menteri Pekerjaan Umum Nomor : 13 /PRT/M/2011 Tentang Tata Cara Pemeliharaan Dan Penilikan Jalan , 2011

Peraturan Pemerintah Republik Indonesia No. 26 tahun 1985 tentang Jalan. Direktorat Jenderal Bina Marga

Peraturan Pemerintah Republik Indonesia No. 43 tahun 1993 tentang Prasarana Jalan dan Lalu Lintas Jalan

Rahmat, ST., MT. (2017). Laporan Evaluasi Kondisi Jalan Lingkungan Rumah Sakit Umum Daerah Dr. Kanujoso Djatiwibowo 